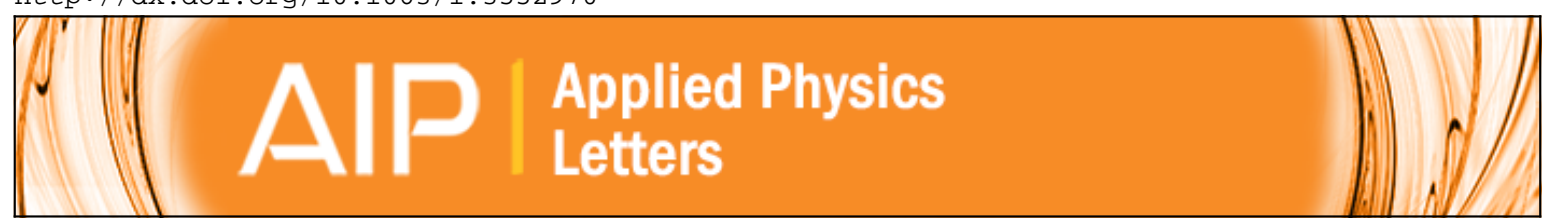

\title{
Low-frequency nanotesla sensitivity in Metglas/piezoelectric/carbon fiber/piezoelectric composites with active tip mass
}

Chee-Sung Park, Dragan Avirovik, Scott Bressers, and Shashank Priya

Citation: Applied Physics Letters 98, 062904 (2011); doi: 10.1063/1.3552970

View online: http://dx.doi.org/10.1063/1.3552970

View Table of Contents: http://scitation.aip.org/content/aip/journal/apl/98/6?ver=pdfcov

Published by the AIP Publishing

\section{Articles you may be interested in}

Magnetoelectric effect of the multi-push-pull mode in $0.35 \mathrm{~Pb}(\ln 1 / 2 \mathrm{Nb} 1 / 2) \mathrm{O} 3-0.35 \mathrm{~Pb}(\mathrm{Mg} 1 / 3 \mathrm{Nb} 2 / 3) \mathrm{O} 3-$

$0.30 \mathrm{PbTiO} /$ Metglas magnetoelectric composite

J. Appl. Phys. 114, 027011 (2013); 10.1063/1.4812221

Piezoelectric single crystal langatate and ferromagnetic composites: Studies on low-frequency and resonance magnetoelectric effects

Appl. Phys. Lett. 100, 052901 (2012); 10.1063/1.3679661

Large magnetoelectric coupling coefficient in poly(vinylidene fluoride-hexafluoropropylene)/Metglas laminates J. Appl. Phys. 110, 104103 (2011); 10.1063/1.3660767

High magnetic field sensitivity in $\mathrm{Pb}(\mathrm{Zr}, \mathrm{Ti}) \mathrm{O} 3-\mathrm{Pb}$ ( Mg 1 / 3 Nb 2 / 3 ) O 3 single crystal/TerfenolD/Metglas magnetoelectric laminate composites

J. Appl. Phys. 107, 094109 (2010); 10.1063/1.3406142

Influence of electric voltage bias on converse magnetoelectric coefficient in piezofiber/Metglas bilayer laminate composites

J. Appl. Phys. 106, 054114 (2009); 10.1063/1.3212993

\section{AAP Re-register for Table of Content Alerts}




\title{
Low-frequency nanotesla sensitivity in Metglas/piezoelectric/carbon fiber/piezoelectric composites with active tip mass
}

\author{
Chee-Sung Park, Dragan Avirovik, Scott Bressers, and Shashank Priya ${ }^{\text {a) }}$ \\ Center for Energy Harvesting Materials and Systems (CEHMS), Virginia Polytechnic Institute and State \\ University, Blacksburg, Virginia 24061, USA
}

(Received 22 December 2010; accepted 10 January 2011; published online 8 February 2011)

\begin{abstract}
We report nanotesla sensitivity in Metglas/piezoelectric/carbon fiber/piezoelectric laminates with active tip mass operating in the vicinity of second bending mode. The peak magnetoelectric response for the laminate with an active tip mass $(1 \mathrm{~g})$ in longitudinal-transversal mode under $\mathrm{H}_{\mathrm{dc}}=8$ Oe and $\mathrm{H}_{\mathrm{ac}}=1$ Oe was found to be $\sim 1.08 \mathrm{~V} / \mathrm{cm} \mathrm{Oe}$ at $43 \mathrm{~Hz}$ (first bending mode) and $\sim 19 \mathrm{~V} / \mathrm{cm}$ Oe at $511 \mathrm{~Hz}$ (second bending mode). At the standard $1 \mathrm{kHz}$ frequency, the maximum resolution of $5 \mathrm{nT}$ was measured under $\mathrm{H}_{\mathrm{ac}}=0.5$ Oe. (C) 2011 American Institute of Physics. [doi:10.1063/1.3552970]
\end{abstract}

It is well-known now that laminate composite consisting of magnetostrictive and piezoelectric layers provide high magnetoelectric (ME) properties. ${ }^{1-4}$ High-performance piezoelectric and magnetostrictive materials (i.e., single crystals) can enhance the ME response but are expensive. Structural resonance can be utilized to increase the ME response while using polycrystalline materials, but for a reasonable size transducer, the resonance lies in a high frequency regime. ${ }^{5-7}$ The electromechanical resonance (EMR) frequency of a piezoelectric layer in a cantilever structure can be shifted by either changing the capacitance of the piezoelectric layer or by using the effective tip mass. ${ }^{7,8}$ The increase in passive tip mass (nonmagnetic) leads to lower resonance frequency but at the same time it decreases the overall magnitude of ME response. ${ }^{7}$ In order to overcome these problems, we investigate in this letter (i) the effect of the higher order bending modes, (ii) the effect of the rigid clamping on the response of fixed-free cantilever beam, and (iii) the effect of the active tip mass (ferromagnetic).

Piezoelectric stripes (600/200/0.60-SA, APC International Ltd., USA) with dimensions of $60 \times 20 \times 0.6 \mathrm{~mm}^{3}$ were selected as the base structure. The stripes themselves consisted of a carbon fiber substrate (C) bonded between two layers of lead zirconate titanate (PZT)-5X45 (P). On top of piezoelectric layer, a $100 \mu \mathrm{m}$ thick Metglas (2605SA1, Metglas Inc., USA) layer (M) was bonded using epoxy (West System, USA) with a curing temperature of $80^{\circ} \mathrm{C}$ (MPCP laminate). Four different configurations with varying tip masses were investigated. The initial configuration had no tip mass and therefore acts as a reference for comparative analysis. The second configuration had a $1 \mathrm{~g}$ "passive" or nonmagnetic tip mass made from PZT ceramic. For the third and fourth configuration, 1 and $2 \mathrm{~g}$ "active" nickel (Ni) tip masses were utilized.

Figure 1(a) shows the impedance versus frequency behavior for the unclamped (free-free) and clamped (fixed-free) MPCP laminate. The rigid clamping resulted in sharp resonance behavior at low frequency and thus was used for further investigations. Figure 1(b) shows the variation of magnetostriction and piezomagnetic coefficient of the MPCP

\footnotetext{
a) Author to whom correspondence should be addressed. Electronic mail: spriya@vt.edu.
}

laminate as a function of a dc magnetic field $\left(\mathrm{H}_{\mathrm{dc}}\right)$. The coefficients $\lambda_{11}$ and $\lambda_{12}$ correspond to in-plane magnetostriction coefficients measured parallel and perpendicular to applied $\mathrm{H}_{\mathrm{dc}}$. When $\mathrm{H}_{\mathrm{dc}}$ was applied in the longitudinal direction of the specimen, the Metglas elongated in the same direction by $28 \mathrm{ppm}$ and contracted in the lateral direction by $22 \mathrm{ppm}$. The parameters $\mathrm{q}_{11}$ and $\mathrm{q}_{12}$ are in-plane piezomagnetic coefficients $\left(\mathrm{q}_{\mathrm{ij}}=\mathrm{d} \lambda_{\mathrm{ij}} / \mathrm{dH}\right)$. The maximum $\mathrm{q}_{11}$ and $\mathrm{q}_{12}$ were obtained at $\mathrm{H}_{\mathrm{dc}}=8$ Oe with values of 1.08 and $-0.75 \mathrm{ppm} / \mathrm{Oe}$, respectively. Thus, low-field saturated ME behavior and high ME coefficient for MPCP laminate can be expected. ${ }^{5,9}$ The functional change of piezomagnetic coefficients has resemblance to the measured ME voltage coefficient. The peak in ME coefficient of $394 \mathrm{mV} / \mathrm{cm}$ Oe was achieved at a low dc bias field of $\mathrm{H}_{\mathrm{dc}}=7.7$ Oe. Based on the measurement of impedance and phase angle, the laminate was found to exhibit
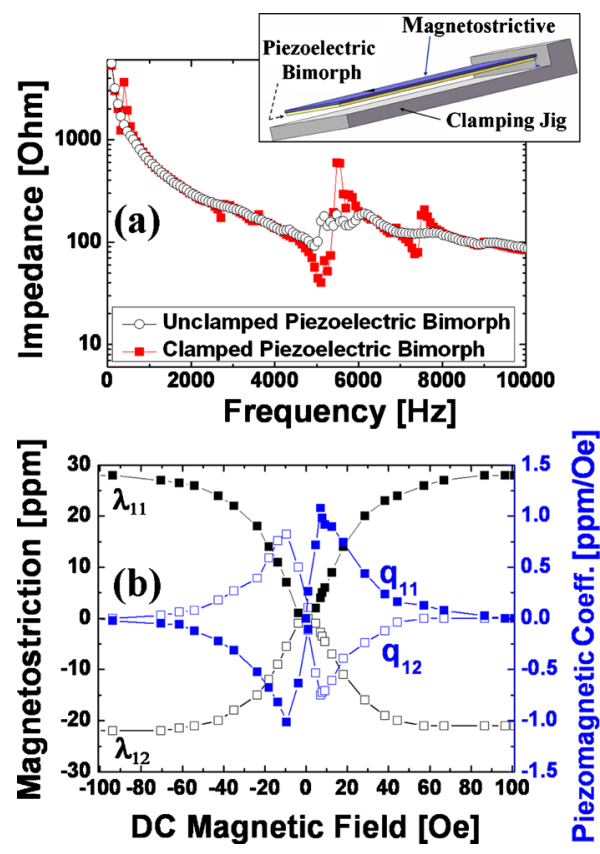

FIG. 1. (Color online) (a) Impedance spectrum of PCP laminate measured using impedance analyzer in unclamped and clamped (cantilever beam) configurations. Inset: CAD model of MPCP with clamping condition. (b) Magnetostriction and piezomagnetic coefficient for varying magnitude of $\mathrm{dc}$ magnetic field. 

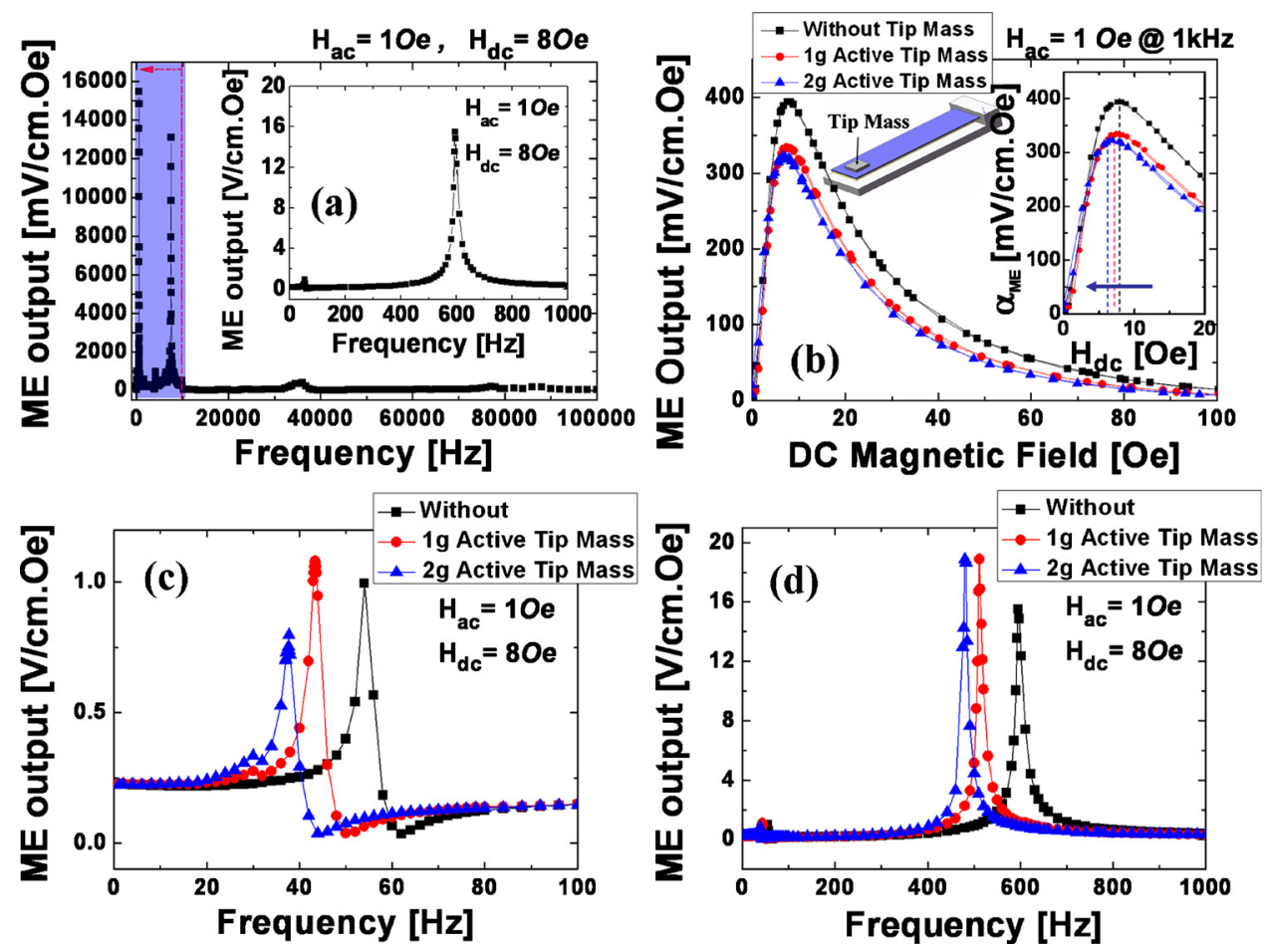

FIG. 2. (Color online) (a) Measured ME output of MPCP laminate without tip mass as a function of excitation frequency with applied ac magnetic field of 1 Oe. The large magnitude of the first two bending modes can be clearly seen in the inset. (b) ME voltage output as a function of dc magnetic field under the condition of $\mathrm{H}_{\mathrm{ac}}$ $=1 \mathrm{Oe}$ at $1 \mathrm{kHz}$ with multiple active tip mass configurations. (c) ME voltage output as a function of frequency around the first bending mode. (d) Second bending mode for various tip mass configurations. the first bending resonance at $54 \mathrm{~Hz}$ and the second bending resonance at $595 \mathrm{~Hz}$.

The ME response of laminate as a function of frequency was measured under the conditions of $\mathrm{H}_{\mathrm{ac}}=1$ Oe and $\mathrm{H}_{\mathrm{dc}}$ $=8 \mathrm{Oe}$, as shown in Fig. 2(a). The maximum ME response of 15.5 and $13.1 \mathrm{~V} / \mathrm{cm}$ Oe was obtained at 595 and $7549 \mathrm{~Hz}$. The first ME resonant peak occurred at $54 \mathrm{~Hz}$ with the magnitude of $1 \mathrm{~V} / \mathrm{cm}$ Oe. ME coefficients depending on the active mass were measured as a function of dc magnetic field under the constant condition of $\mathrm{H}_{\mathrm{ac}}=1$ Oe at $f=1 \mathrm{kHz}$, as shown in Fig. 2(b). The peak ME value without tip mass was measured to be $394 \mathrm{mV} / \mathrm{cm}$ Oe at $1 \mathrm{kHz}$. With $1 \mathrm{~g}$ active tip mass, this magnitude was reduced to $333 \mathrm{mV} / \mathrm{cm}$ Oe, while with $2 \mathrm{~g}$ active tip mass, it was further decreased to 322 $\mathrm{mV} / \mathrm{cm}$ Oe. The ME peak position decreased from 7.7 to 7 Oe with increase in active tip mass from 0 to $2 \mathrm{~g}$. However, the traces of ME coefficients up to 4.5 Oe were identical as seen in Fig. 2(b).

The shift in EMR frequency depending on the magnitude of active tip mass was quantified by impedance measurements. The first bending mode was found to occur at $54 \mathrm{~Hz}$ without tip mass, which decreased to $43 \mathrm{~Hz}$ upon addition of $1 \mathrm{~g}$ tip mass and further decreased to $37 \mathrm{~Hz}$ by adding $2 \mathrm{~g}$ tip mass. The second bending mode at $595 \mathrm{~Hz}$ moved down to 511 and $480 \mathrm{~Hz}$ with the addition of 1 and $2 \mathrm{~g}$ tip masses, respectively. ME behavior depending on the magnitude of active tip mass was measured as a function of frequency under the constant conditions of $\mathrm{H}_{\mathrm{ac}}=1$ Oe and $\mathrm{H}_{\mathrm{dc}}=8$ Oe. The peak ME positions in Fig. 2(c) were well matched to the EMR results. The ME output voltage coefficient of 1 $\mathrm{V} / \mathrm{cm}$ Oe at $54 \mathrm{~Hz}$ increased to $1.08 \mathrm{~V} / \mathrm{cm}$ Oe at $43 \mathrm{~Hz}$ with $1 \mathrm{~g}$ tip mass, but decreased to $0.8 \mathrm{~V} / \mathrm{cm}$ Oe at $37 \mathrm{~Hz}$ with $2 \mathrm{~g}$ tip mass, as shown in Fig. 2(c). For the second bending mode, ME output voltage of $15.5 \mathrm{~V} / \mathrm{cm} \mathrm{Oe}$ at $595 \mathrm{~Hz}$ increased to $19 \mathrm{~V} / \mathrm{cm} \mathrm{Oe}(22 \%)$ for both 1 and $2 \mathrm{~g}$ tip masses, as shown in Fig. 2(d). For the first bending mode, the $1 \mathrm{~g}$ active tip mass configuration exhibited the best ME output.
For the second bending mode, both 1 and $2 \mathrm{~g}$ active tip masses effectively increased the ME coefficient. These results clearly demonstrate that the second bending mode can be effectively tuned without any severe drop in ME output voltage by using the active tip mass. For comparison, a fourth configuration of MPCP laminate was fabricated with $1 \mathrm{~g}$ nonactive tip mass. In this case, the ME peak position increased from 7.7 to $8.3 \mathrm{Oe}(\sim 0.6 \mathrm{Oe})$ and the $\mathrm{ME}$ mag-

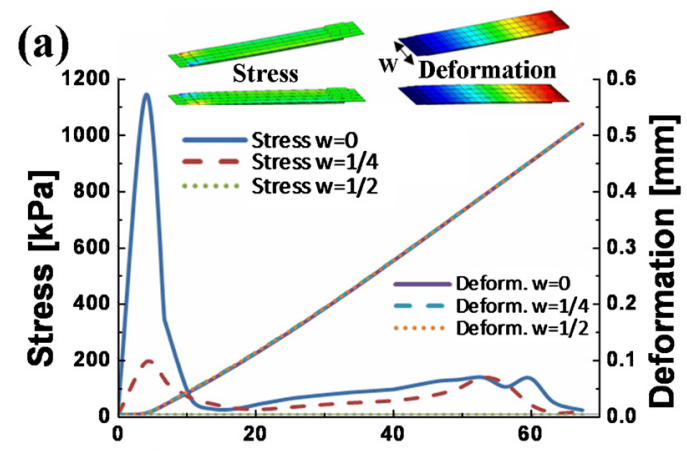

ME Composite Beam Length [mm]

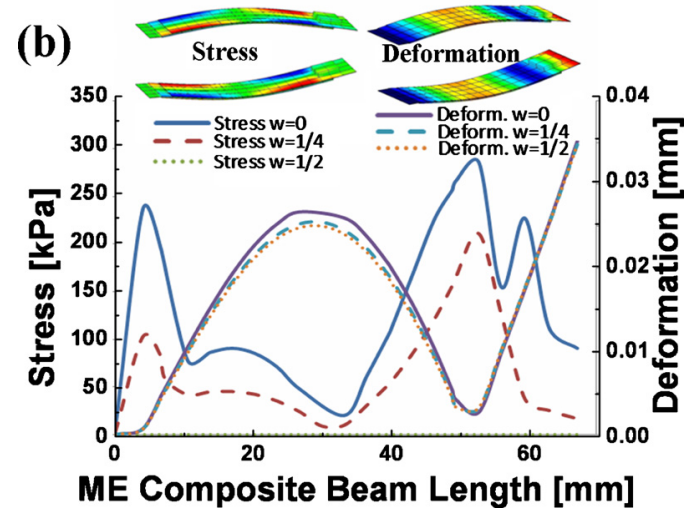

FIG. 3. (Color online) Stress and deformation distribution along the length of the MPCP laminate with $1 \mathrm{~g}$ active tip mass (a) at the first bending mode and (b) at the second bending mode. 


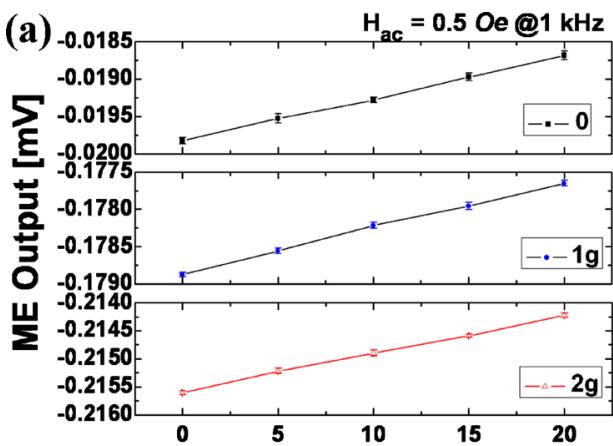

(c)
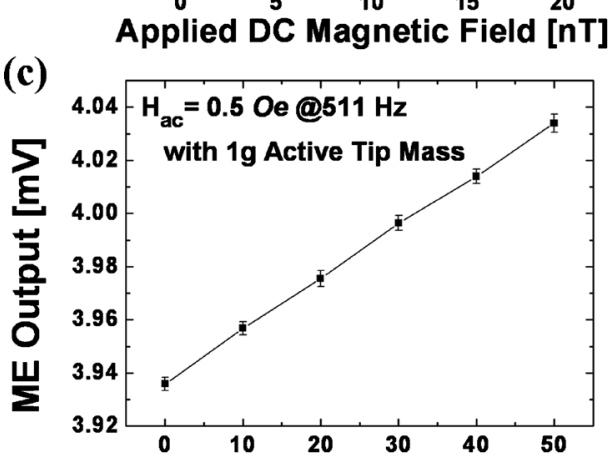

Applied DC Magnetic Field [nT]

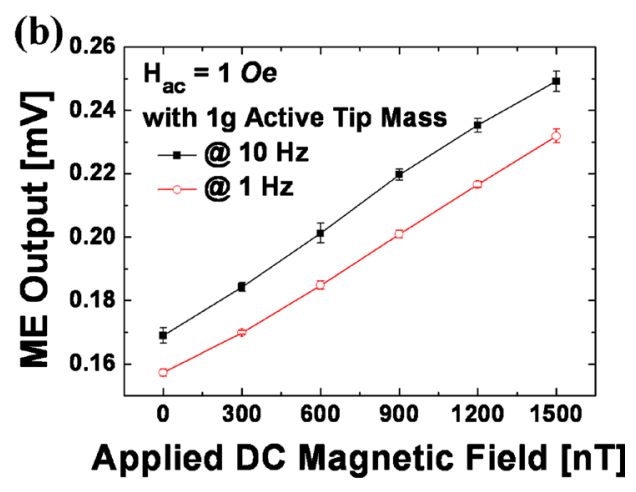

(d)

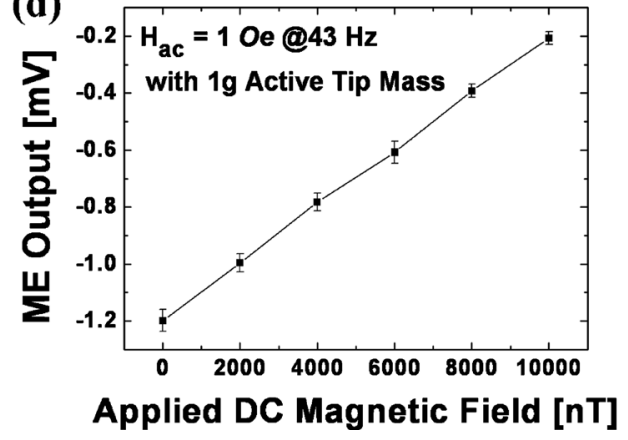

FIG. 4. (Color online) ME output voltage corresponding to an applied small dc magnetic field: (a) $5 \mathrm{nT}$ under the constant condition of $\mathrm{H}_{\mathrm{ac}}=0.5 \mathrm{Oe}$ at $f=1 \mathrm{kHz}$ with/without active tip mass; (b) $300 \mathrm{nT}$ under $\mathrm{H}_{\mathrm{ac}}=1$ Oe at $f=10$ and $1 \mathrm{~Hz}$ with $1 \mathrm{~g}$ active tip mass; (c) and (d) ME response with a $1 \mathrm{~g}$ active tip mass operating in the second and first modes; (c) $10 \mathrm{nT}$ under $\mathrm{H}_{\mathrm{ac}}=0.5$ Oe at $f=511 \mathrm{~Hz}$; and (d) $2 \mu \mathrm{T}$ under $\mathrm{H}_{\mathrm{ac}}=0.5$ Oe at $f=43 \mathrm{~Hz}$. nitude decreased by $14 \%$. Both these effects are undesirable. Further, the initial slope of ME curve was also decreased.

Using ATILA finite element method, the first bending mode for MPCP laminate with $1 \mathrm{~g}$ tip mass was calculated to be $51 \mathrm{~Hz}$, which is slightly different from experimentally measured $43 \mathrm{~Hz}$. Since ideal clamping is not possible in an experimental setting, a small variation is expected. A second bending mode for the structure was calculated to be $502 \mathrm{~Hz}$. Two main analyses were conducted using ATILA: (i) stress along various directions (XX, YY, ZZ, XY, XZ, and YZ) and (ii) deformation along the length. The analyses are shown in Figs. 3(a) and 3(b). In both figures, the $x$-axis represents the length of the MPCP laminate and the $y$-axis represents the shear stress distribution in the XY direction (left) and deformation (right). The MPCP laminate was symmetrical across the width (w); therefore, the stress and deformation along the length of the beam is reported at three sections $w=0$, $\mathrm{w}=1 / 4$, and $\mathrm{w}=1 / 2$. At the first bending mode in Fig. 3(a), the stress levels are the highest only near the clamped end of the beam. Further, it can be noticed that the stress across the width was highest at $\mathrm{w}=0$ and it decreases toward the center of the beam $w=1 / 2$. Figure $3(\mathrm{~b})$ shows the stress and deformation distribution of the MPCP laminate at second bending mode. In this case, the highest deformation is seen at half the length of the ME laminate from its free end. The second mode also produces two widely and highly stressed areas which are the main reasons behind higher voltage output.

The maximum resolution for detecting a small dc magnetic field was found to be $5 \mathrm{nT}$ under $\mathrm{H}_{\mathrm{ac}}=0.5$ Oe at $f=1 \mathrm{kHz}$, regardless of active tip mass as shown in Fig. 4(a). The constant resolutions regardless of active tip mass configurations were mainly due to the same slope of $\mathrm{ME}$ responses from 0 to $4.5 \mathrm{Oe}$, as confirmed in Fig. 2(b). The steep slope from zero to saturation bias provides high sensitivity to small dc magnetic field. These results confirm the effectiveness of active tip mass. At both 1 and $10 \mathrm{~Hz}, 300 \mathrm{nT}$ resolution was obtained with $1 \mathrm{~g}$ tip mass as shown in Fig. 4(b). When we applied small dc bias to the composite at the second resonance of $511 \mathrm{~Hz}$ with $1 \mathrm{~g}$ active tip mass, $10 \mathrm{nT}$ resolution was obtained under $\mathrm{H}_{\mathrm{ac}}=0.5$ Oe at $f=1 \mathrm{kHz}$, as shown in Fig. 4(c). The laminate showed $2 \mu \mathrm{T}$ resolution at the first bending mode of $43 \mathrm{~Hz}$, as shown in Fig. 4(d). Interestingly, the $\mathrm{ME}$ sensing margin at second resonance is much higher, though the detecting resolution is similar to that at $1 \mathrm{kHz}$. These results clearly show the promise of operating at second bending mode.

In summary, we demonstrate a low-frequency highsensitivity magnetic field sensor. By using active mass, the first and second bending mode were obtained at 37 and 480 $\mathrm{Hz}$ with peak ME coefficient of 1.1 and $19 \mathrm{~V} / \mathrm{cm}$ Oe, respectively.

This work was financially supported by DARPA (Grant No. FA8650-09-1-7945), Army Research Office (Grant No. 47576MS), and the Office of Basic Energy Science, Department of Energy, USA (Grant No. DE-FG02-08ER46484).

${ }^{1}$ T. Kimura, T. Goto, H. Shintani, K. Ishizaka, T. Arima, and Y. Tokura, Nature (London) 426, 55 (2003)

${ }^{2}$ N. A. Spaldin and M. Fiebig, Science 309, 391 (2005).

${ }^{3}$ J. Ryu, S. Priya, K. Uchino, and H.-E. Kim, J. Electroceram. 8, 107 (2002).

${ }^{4}$ C.-W. Nan, M. I. Bichurin, S. Dong, D.Viehland, and G. Srinivasan, J. Appl. Phys. 103, 031101 (2008).

${ }^{5}$ D. V. Chashin, Y. K. Fetisov, K. E. Kamentsev, and G. Srinivasan, Appl. Phys. Lett. 92, 102511 (2008).

${ }^{6}$ S. Dong, J. Zhai, J. Li, and D. Viehland, Appl. Phys. Lett. 89, 252904 (2006)

${ }^{7}$ C.-S. Park, C.-W. Ahn, S.-C. Yang, and S. Priya, J. Appl. Phys. 106, 114101 (2009).

${ }^{8}$ D. Charnegie, M.S. thesis, University of Pittsburgh, PA, 2005

${ }^{9}$ G. Srinivasan, E. T. Rasmussen, and R. Hayes, Phys. Rev. B 67, 014418 (2003). 